\title{
The Pragmatic Connotation of Wittgenstein's Assertion "Language Game is a Form of Life"
}

Peilan Peng ${ }^{1,2}$

${ }^{1}$ Beijing Institute of Petrochemical Technology, Beijing 102617, China.

${ }^{2}$ Beijing Foreign Studies University, Beijing 100089, China.

Abstract: This paper introduces the concept of "language game", and on the basis of this background, illustrates the two important concepts of the later philosophy Wittgenstein: "language game" and "life form", and emphatically discusses the "language game" and "life form" of the dialectical relations. The paper also reveals the pragmatic connotation of the assertion "language is a kind of life form", which is mainly reflected in the following three aspects: language use is unique to human social practice; the context of linguistic games is life; the rules of the language game are rooted in the forms of life.

Keywords: Language Games; Life Style; Pragmatic Connotation; Social Practice Activities

\section{Introduction}

It is this essential structural commonality that makes it possible for language to describe the world and propositions can be logical images of facts. And our thoughts make this possibility a reality. However, by the late 1920s and early 1930 s, Wittgenstein began to realize that his previous view of language and the world was too arbitrary and one-sided to conform to the real situation of our language and world. The basic proposition characterized by interdependence, as he had said before, did not exist. Similarly, our world does not have the essential structure described previously. Wittgenstein abandoned his previous ultimately about "language" and the definition of the "essence" of the world. Similarly, the "world" is not a closed and completed whole composed of all describable facts, but a heterogeneous conglomeration of various forms of life with different functions but interwoven premises. ${ }^{[1]}$

\section{Wittgenstein's explanation of "language game" and "life form"}

"Language game theory" is the core of Wittgenstein's later philosophy of language, and it is also the watershed between his early philosophy and his later philosophy. The primary languages are simple activities or reactions, such as reading and recognizing objects, greeting, telling stories, singing, etc., or words spoken in simple games of life, such as hide-and-seek or rubber band jumping, which children sing while playing. Everyday language is based on the original language."By gradually adding new forms, we can construct complex forms from the original." ${ }^{[2]}$ That is to say, no matter what kind of language form or content, people's understanding of language must start from daily life, which is the main characteristic of "language game". Like "language game", we are hard to find in Wittgenstein's philosophy research to a clear definition of the "life form", only by Wittgenstein in his book on the concrete application of the concept of refining and summarized: namely "conditions prevailing in the particular historical background, inherited in a specific historical custom, habit, system, transmission and so on the basis of people's way of thinking and behavior of the overall or local" ${ }^{[3]}$ That is to say, life form is the sum total of all kinds of life

This is an open-access article distributed under the terms of the Creative Commons Attribution Non-Commercial License (http://creativecommons. org/licenses/by-nc/4.0/), which permits unrestricted non-commercial use, distribution, and reproduction in any medium, provided the original work is properly cited. 
practices recognized and Shared by members of different groups in human society. In his Philosophical Studies, Wittgenstein often regards expectation, intention, meaning, understanding, feeling and other psychological activities as life forms, which become life forms because people live together and use language ${ }^{[4]}$ Language is the main way for people to communicate their feelings, information and ideas, and constitutes an important part of their lives. Later Wittgenstein believed that we all use language in the context of "life", but it cannot transcend life. People can only understand and use language correctly in the way they live.

\section{The dialectical relationship between "language game" and "life form"}

Through the explanation of the two concepts of "language game" and "life form", it is not difficult to find the consistency and similarity between them in many aspects. First of all, they are based on human social practice activities; secondly, they are the original beings in life. In addition, both of them are specific with the attribute of "no essence". Neither "language games" nor "life forms" can be defined by a certain explanation or definition. The similarity between different members of the same family is a loose, disordered and complex netlike relationship. Of course, although "language game" and "life form" are closely related, as two different concepts, they have their own meanings. This difference can be roughly summarized as follows: "language game" is a part and embodiment of "life form". It is through the description of the language game that life forms can be shown and embodied into various language games. The concept of "form of life" not only emphasizes our linguistic activities, but also embodies the cultural background of human life, which in turn provides the foundation for the evolving linguistic games throughout history. ${ }^{[5]} \mathrm{As}$ "language games" are closely related to "life forms", the rich and colorful life forms will inevitably lead to the diversity of language games. It is obvious that all human language and behavior originate from practical activities in real life. Different forms of life give different meanings to practical activities. Language, as a unique expression means of human beings, is not only closely related to human practical activities, but also runs through the daily life form of human beings. ${ }^{[6]}$ This fully demonstrates the inseparability of "language game" and "life form". Furthermore, the dialectical relationship between "life form" and "language game" is also reflected in their mutual integration and embodiment. Language and life are both diversified. It is generally believed that the relationship between "language game" and "life form" is the one between part and whole, that is, they are different in content. "Life form" includes "language game", but is not limited to "language game".'"Language play" is the most important part of people's life form. In addition, the dialectical relationship between "language game" and "life form" is also reflected in another important characteristic, namely "obeying rules". There is a great deal of similarity in "following the rules". Any kind of game must abide by certain rules, rooted in human social practice. Obviously, they follow privately agreed rules of chess which is not what we would call "following the rules", because it is not rooted in life form and detached from social practice. Wittgenstein's discussion on the rule-abiding nature of language games is mainly reflected in the following two aspects: First, the process of rule-abiding is blind. By "following the rules blindly," he meant that following the rules was a natural, undirected behavior. Second, Wittgenstein also insisted that obeying rules is a habit, that is, some kind of repetitive and regular behavior."Obeying the rules" is also a kind of language game in the living form. Both obeying the rules and language games must be understood and explained in the context of people's living form. "Living form", as the background and basis of covering the "language game", must also abide by the rules itself.

\section{The pragmatic connotation "Language game is a form of life" of Wittgenstein}

Wittgenstein regards "language game" as a whole composed of language and actions interwoven with language. He pointed out that "life form" is something that people cannot choose by themselves, but also something they have to accept and adapt to, including traditions, customs, beliefs, behavior patterns, etc., because we can only live in the formed life form and live in the formed cultural background. As a "life form", "language game" is a transcendent existence that people cannot choose and must accept. Wittgenstein's "Pragmatic connotation of language as a way of life" is mainly reflected in the following aspects:

First of all, Wittgenstein's assertion that "language game is the pragmatic connotation of a form of life" is reflected in his belief that using language is a unique social practice of human beings. There are two aspects to this practice. First of all, "language games" are language activities, including some behaviors, actions and social practices. Second, games are not empty relationships between words, but part of people's social activities in the real world. All kinds of language games constitute 
the whole language practice and become part of the life form. The original forms of language are woven together with other human activities. People learn to speak in scenes and understand the meaning of sentences in scenes."I can say that language is based on a way of life. To describe this linguistic phenomenon, we must describe any kind of practice, but not an isolated event." ${ }^{9[7]}$ In fact, language games constantly generate and change, which is not only the source of language generation, but also the foundation of language formation."New types of languages, new language games are created, while others gradually become obsolete and forgotten." ${ }^{,[8]}$ The change of life form inevitably leads to the change of language practice, while the change of language game is actually the change of life form. The mastery of language skills, in essence, is also a kind of life technology. Just like learning your mother tongue, acquiring your mother tongue is a skill that you learn in life. Secondly, the conclusion that "language game is the pragmatic connotation of a form of life" is also reflected in the fact that the context of language game is life. In Wittgenstein's later period, he paid more attention to the study of daily language in life, and language was directly related to life. At this time, the world was the world of life. Moreover, we live through language, and language is the dimension of life itself. Our linguistic game is our linguistic life, and therefore we are necessarily linguistic animals. Since the use of words can only be carried out in related life forms, without the use of "language game" in this form of life, the meaning of words and sentences cannot be discussed. Finally, "language game is the pragmatic connotation of a form of life" is also reflected in "rules of language game are rooted in the form of life". How people use language ultimately depends on the customs, habits and other aspects of the language community in which people live — The life form in which people live. In a word, Wittgenstein wanted to express the view that "the narration of language is an activity or a part of the life form. We cannot understand the nature of language in isolation from its activities." $[9]$

\section{Conclusion}

The study of language cannot be separated from life, for it is rooted in life. Although there has never been a fixed definition of "life form", it has been endowed with richer connotation and broad extension by scholars, and the understanding of this meaning is exactly consistent with various daily life styles of human beings. As a social phenomenon, language is understood and mastered by people in these various ways of life. What form of life people live on determines what language they use. "Forms of life" vividly illustrates its rationale and value, and at the same time provides a fertile soil and diversified environment for the use of "language play".

\section{References}

1. Han LH. Wittgenstein's theory on "language games" and "life forms". Journal of Peking University (Philosophy and Social Sciences edition) 1996; (1): 101-108.

2. Wittgenstein L. The blue and brown books. Oxford: Basil Black well 1980: 17.

3. Han LH. Wittgenstein's philosophical road. Kunming: Yunnan University Press 1996: 143.

4. Tu JL. A study of wittgenstein's later philosophical thought. Wuhan: Wuhan University Press 2007: 15.

5. Lu HY. Later wittgenstein's view of context: "linguistic games" and "life forms". Journal of Huaibei Normal University (Philosophy and Social Sciences edition) 2014; (5): 147-150.

6. Fan B. Reflection on wittgenstein's language game theory. Journal of Foreign Languages 2013; (4): 88-91.

7. Jiang Y. Wittgenstein: A post-philosophical culture. Beijing: Social Sciences Academic Press 2002; 113: 4-5.

8. Wittgenstein. Research in philosophy. Beijing: Commercial Press 1996: 17-18.

9. Cui D. An analysis of wittgenstein's linguistic philosophy. Northern Treatise 2011; (5): 122-125. 